
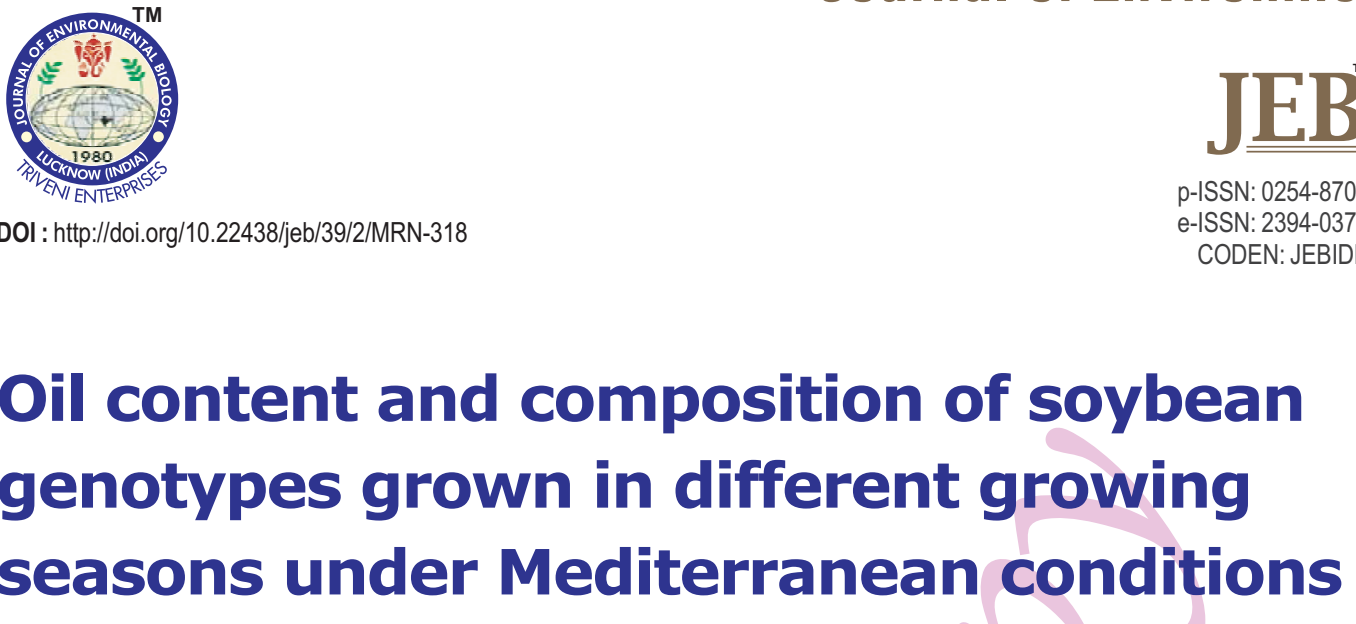

\title{
Oil content and composition of soybean genotypes grown in different growing seasons under Mediterranean conditions
}

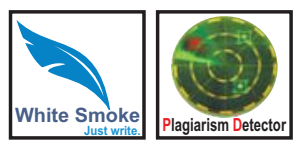

Authors Info

L. Gulluoglu' H. Bakal and H. Arioglü ${ }^{2 *}$

'Vocational School of Ceyhan, Cukurova University, 01330, Adana, Turkey

${ }^{2}$ Department of Field Crops, Faculty of Agriculture, Cukurova University, 01330, Adana, Turkey

${ }^{*}$ Corresponding Author Email : halis@cu.edu.tr

Key words

Edible oil

Fatty acid

Growing seasons

Oil content

Soybean genotypes

Publication Info

Paper received : 30.07 .2016

Revised received: 17.10 .2016

Re-revised received : 29.05.2017

Accepted : 27.06 .2017

\section{Abstract}

Aim : Soybean is a strategic crop plant grown to obtain edible oil and forage. Oil content and fatty acid composition of oilseeds are important consideration for breeding programs. This study was conducted to determinate fatty acid compositions of some soybean varieties grown in both main and double cropping system at the University of Cukurova, Turkey in 2013 and 2014 growing seasons.

Methodology : The experiment was designed in a Randomized Complete Block with three replications. Soybean varieties Atakisi, Arısoy, Cinsoy, Adasoy, Ilksoy, Turksoy, Ataem-7, Sa 88, S4240, Blaze and Nova (maturity group III and IV) were used as a plant material. Oil content and fatty acid (palmitic, stearic, oleic, linoleic and linolenic acids) compositions of soybean varieties were investigated.

Results : According to a two-year average, the fatty acid composition of soybean varieties ranged from $10.59-12.09 \%$ for palmitic acid, $3.11-4.52 \%$ for stearic acid, $27.02-34.09 \%$ for oleic acid, $44.51-51.80 \%$ for linoleic, and $4.44-5.61 \%$ for linolenic acid in main cropped soybean. In double cropped soybean, the fatty acid composition (two-year average) of the tested varieties ranged from 10.76-12.23\% for palmitic acid, $3.94-4.87 \%$ for stearic acid, $22.69-29.51 \%$ for oleic acid, $48.40-54.14 \%$ for linoleic and $5.41-6.62 \%$ for linolenic, respectively.

Interpretation : The oil and oleic acid content was found higher in main cropped than double cropped growing season, but the linoleic acid content was higher in double cropped than in main cropped growing seasons.

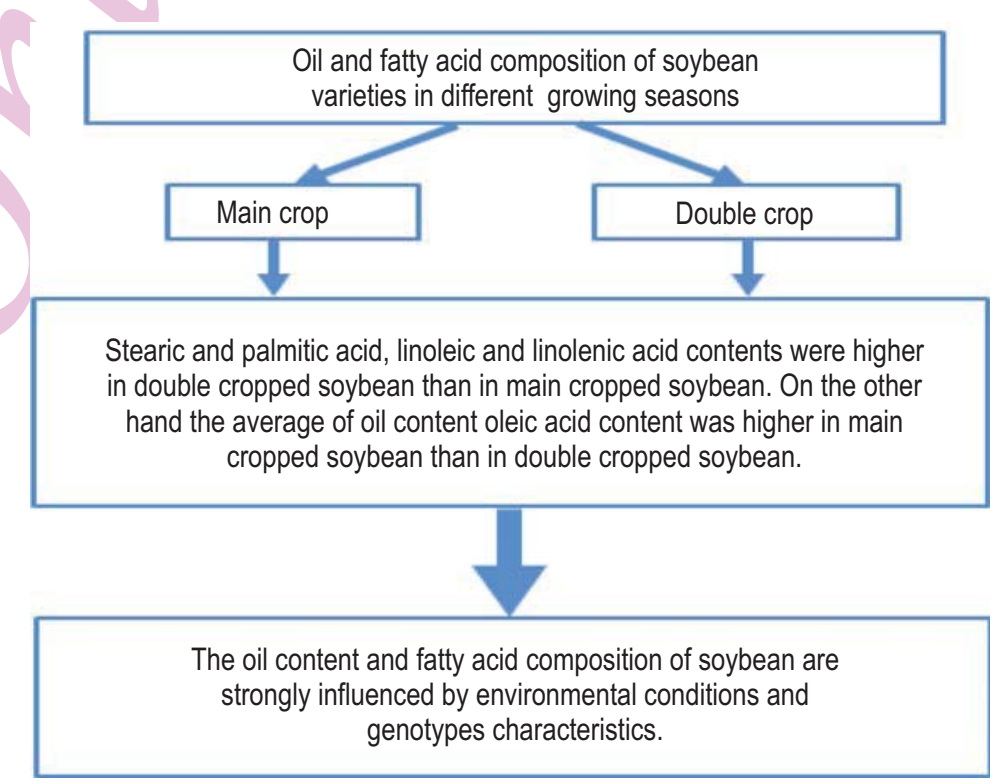




\section{Introduction}

Soybean is a valuable edible oilseed and protein crop (Wilson, 2004). It is a multipurpose plant with much appreciated nutritional and functional characteristics. For last few decades several studies have been carried out to improve its cultivation and properties. Additionally, having a great potential of energyprotein malnutrition eradication, it can contribute greatly to edible oil pool in the region (Sultan et al., 2015). It is cultivated as rotational crop to increase the fertility of soil by fixing atmospheric nitrogen (Sarnaik et al., 2006).

Soybean seeds contain $18-24 \%$ oil, $36-40 \%$ protein, $26 \%$ carbohydrates and $8 \%$ minerals (Arioglu, 2014). For this reason, it is an important source of edible vegetable oil and high quality vegetable protein for human nutrition and animal feeding in the world. Moreover, soybean oil contains important fatty acids that regulate the lipid and oil metabolism in human body. It contains saturated fatty acids (16\%), unsaturated fatty acids (84\%), $24 \%$ monounsaturated fatty acids (oleic) and $60 \%$ polyunsaturated fatty acids (linoleic and linolenic). Soybeans are considered to be essential to because of high percentage of these poly unsaturated fatty acids (Neff and List, 1999).

Fatty acid composition of soybean oils is not constant. The composition of soybean seed depends on several factors like genotype, growing season, geographic location and agronomic implementation. Jung et al. (2012) found that oleic acid was significantly influenced by temperature increase, while the concentration of linoleic and linolenic acid was reduced. Water stress and high temperature altered seed oil composition by increasing C18:1 and decreasing C18:2 and C18:3 concentrations (Bellaloui et al., 2013). Severe water stress or high temperature resulted in higher C16:0 and low C18:0. Genotypes differed in their responses to water stress or temperature.

Soybean genotypes with improved fatty acid profile are being targeted for commercial production. Late planting (June planting) have resulted in an increase of protein concentration with low oil concentration. The high oleic acid and low linolenic acid concentrations during early planting (April planting) and the low oleic acid and high linolenic acid during late planting, especially in June, could be due to the inverse relationship between these two constituents and temperature differences (Bellaloui et al., 2015). In view of the above, soybean was grown as a main and double crop after harvesting small grain in the Cukurova prefecture. The aim of the present study was to determine the fatty acids composition of some soybean varieties widely grown as main and double cropping systems in Turkey.

\section{Materials and Methods}

Plant material and growing conditions : Field experiments were conducted in 2013 and 2014 as a main crop and double crop after wheat harvesting at the research farm of Cukurova University, Adana, Turkey. Indeterminate soybean varieties
Atakisi, Arısoy, Cinsoy, Adasoy, llksoy, Turksoy, Ataem-7, Sa.88, S.4240, Blaze and Nova (group of maturity III and IV) were selected as planting material. The soil textures were clay loam. The soil pH was 7.7 during both years with high content of $\mathrm{K}_{2} \mathrm{O}$ and a low $\mathrm{P}_{2} \mathrm{O}_{5}$ content. The organic matter and nitrogen content were extremely low. The lime content in the upper layers was $22.3 \%$. Air temperature during the investigation time (AprilOctober) ranged between 19.5 to $28.6^{\circ} \mathrm{C}$ and 21.0 to $29.1^{\circ} \mathrm{C}$, where as the rainfall was $89.2 \mathrm{~mm}$ and $172.9 \mathrm{~mm}$ during the growing seasons. The study was designed in a Randomized Complete Block Design with three replication, separately during main and double cropped system. Before sowing, $200 \mathrm{~kg} \mathrm{ha}^{-1}$ of DAP (36 kg ha-1 N, $92 \mathrm{~kg} \mathrm{ha}^{-1} \mathrm{P}$ ) was applied during both the cropping system. Fertilizer requirements were determined based on the basis of nutritional requirements of soybean and soil nutrient availability. In main cropping, planting and harvesting was done in May and mid September, while in double cropping system planting was done in mid June and harvesting in mid October.

Determination of oil content : Seeds of each variety were harvested separately at maturity stage when the seed moisture was reduced to $13 \%$ or less during both growing seasons. Once harvested, seeds were cleaned and dried to approximately $7 \%$ moisture content. Seed oil content in three samples from each genotype was determined by Soxhlet extractor according to AOCS (1990) using petroleum ether $\left(40^{\circ}-60^{\circ} \mathrm{C}\right)$ as solvent. Oil yield per hectare was also calculated.

Determination of fatty acid profiles : Fatty acid profile was measured as fatty acid methyl esters using gas chromatograph (AOCS,1989). Nitrogen was used as a carrier gas at a flow rate of $1.0 \mathrm{ml}$ min-1. Individual peaks were identified by comparing the retention times with grain fatty acid methyl esters.

Statistical analysis : Statistical analysis was performed using the program of MSTAT-C package. Least Significant Differences (LSD) test was used to compare the treatments at probability level of 0.05 .

\section{Results and Discussion}

The average data of 2 year oil content and fatty acids composition of soybean varieties at different growing seasons is presented in Table 1 , Table 2 and Fig. 1 , respectively. Nonsignificant differences were observed in oil content among the soybean varieties studied during growing season. The oil content varied between $18.45-19.99 \%$ in main cropping season and between $17.11-19.37 \%$ in double cropping season. The average oil percentage of soybean varieties was higher in main cropping season (19.01\%) than in double cropping season (18.33\%). The obtained results revealed that high temperature rate during growing season was positive correlated with high oil content. Environment conditions [heat and drought stresses] plays a significant role in seed oil content of soybean (Bellaloui et al., 2015). Several researchers have reported high rate of temperature, especially at pod filling stage increased seed oil content of soybean (Kane et al., 1997; Bellaloui et al., 2011, 2015). 
Table 1 : Oil content and fatty acids composition of some soybean varieties grown as main crop (Two years average)

\begin{tabular}{|c|c|c|c|c|c|c|}
\hline Varieties & Oil content (\%) & Palmitic acid (\%) & Stearic acid (\%) & Oleic acid $(\%)$ & Linoleic acid (\%) & Linolenic acid (\%) \\
\hline Arısoy & 19.36 & $10.80^{f}$ & $3.88^{f}$ & $30.32^{\mathrm{e}}$ & $49.32^{\mathrm{abc}}$ & $4.67^{\mathrm{h}}$ \\
\hline Atakisi & 19.95 & $10.88 e^{f}$ & $4.08^{\mathrm{e}}$ & $27.75^{\mathrm{h}}$ & $51.80^{\mathrm{a}}$ & $5.44^{\mathrm{a}}$ \\
\hline Cinsoy & 18.45 & $11.87^{b}$ & $4.09^{\mathrm{de}}$ & $27.02^{\circ}$ & $50.98^{\mathrm{a}}$ & $5.61^{a}$ \\
\hline Adasoy & 19.99 & $10.60^{9}$ & $3.11^{9}$ & $30.31^{\mathrm{e}}$ & $50.28^{a b}$ & $5.23^{d}$ \\
\hline Ilksoy & 17.69 & $12.04^{\mathrm{a}}$ & $4.52^{\mathrm{a}}$ & $34.09^{a}$ & $44.51^{\mathrm{d}}$ & $4.44^{\prime}$ \\
\hline Turksoy & 19.05 & $10.59^{9}$ & $3.81^{\dagger}$ & $32.92^{b}$ & $47.35^{\mathrm{cd}}$ & $4.76^{9}$ \\
\hline Ataem-7 & 18.57 & $11.55^{c}$ & $4.15^{\mathrm{de}}$ & $28.40^{9}$ & $50.69^{a b}$ & $5.19 d^{e}$ \\
\hline Sa 88 & 18.91 & $11.31^{d}$ & $4.22^{\text {cd }}$ & $29.36^{\dagger}$ & $49.59^{a b c}$ & $5.31^{\mathrm{c}}$ \\
\hline S 4240 & 19.81 & $11.00^{\mathrm{e}}$ & $4.37^{\circ}$ & $27.93^{\text {h }}$ & $51.24^{\mathrm{a}}$ & $5.14^{e}$ \\
\hline Blaze & 19.33 & $11.66^{c}$ & $4.34^{\mathrm{bc}}$ & $31.62^{c}$ & $46.78^{\text {cd }}$ & $4.68^{h}$ \\
\hline Nova & 19.01 & $11.91^{\mathrm{ab}}$ & $4.12^{\text {de }}$ & $30.93^{\mathrm{d}}$ & $48.01^{\mathrm{bc}}$ & $4.92^{f}$ \\
\hline Average & 19.01 & 11.29 & 4.06 & 30.06 & 49.14 & 5.04 \\
\hline LSD (\%5) & NS & 0.222 & 0.197 & 0.395 & 4.106 & 0.082 \\
\hline
\end{tabular}

*Same letters in a column are not significantly difference at 0.05 probability level

Table 2 : Oil content and fatty acids composition of some soybean varieties grown as a double crop (Average of two years )*

\begin{tabular}{|c|c|c|c|c|c|c|}
\hline Varieties & Oil content (\%) & Palmitic acid (\%) & Stearic acid (\%) & Oleic acid (\%) & Linoleic acid (\%) & Linolenic acid (\%) \\
\hline Arısoy & 18.61 & $10.76^{c}$ & $4.64^{\mathrm{ab}}$ & $24.94^{d}$ & $52.99^{\circ}$ & $5.84^{f}$ \\
\hline Atakisi & 19.31 & $10.98^{\mathrm{c}}$ & $4.71^{\mathrm{ab}}$ & $24.06^{\mathrm{e}}$ & $53.24^{c}$ & $6.16^{d}$ \\
\hline Cinsoy & 17.52 & $12.04^{\mathrm{a}}$ & $4.26^{c}$ & $22.69^{9}$ & $53.79^{b}$ & $6.42^{b}$ \\
\hline Adasoy & 19.37 & $10.98^{c}$ & $3.94^{d}$ & $25.75^{\mathrm{c}}$ & $52.18^{f}$ & $6.24^{c}$ \\
\hline Ilksoy & 17.11 & $12.23^{\mathrm{a}}$ & $4.69^{\mathrm{ab}}$ & $27.93^{\mathrm{b}}$ & $48.80^{\mathrm{h}}$ & $5.55^{9}$ \\
\hline Turksoy & 18.23 & $10.85^{\circ}$ & $4.87^{\mathrm{a}}$ & $29.51^{\mathrm{a}}$ & $48.42^{\prime}$ & $5.54^{9}$ \\
\hline Ataem-7 & 18.07 & $11.51^{\mathrm{b}}$ & $4.55^{\mathrm{b}}$ & $24.13^{\mathrm{e}}$ & $53.07^{d}$ & $5.92^{\mathrm{e}}$ \\
\hline Sa 88 & 18.08 & $12.14^{\mathrm{a}}$ & $4.48^{\mathrm{bc}}$ & $22.69^{9}$ & $53.75^{\mathrm{b}}$ & $6.62^{\mathrm{a}}$ \\
\hline S 4240 & 19.15 & $11.25 b^{c}$ & $4.57^{\mathrm{b}}$ & $23.20^{f}$ & $54.14^{\mathrm{a}}$ & $6.12^{d}$ \\
\hline Blaze & 17.98 & $12.18^{\mathrm{a}}$ & $4.59^{b}$ & $27.92^{c}$ & $48.40^{\prime}$ & $5.41^{\mathrm{h}}$ \\
\hline Nova & 18.19 & $12.14^{\mathrm{a}}$ & $4.66^{\mathrm{ab}}$ & $25.90^{\mathrm{b}}$ & $50.57^{9}$ & $5.96^{\circ}$ \\
\hline Average & 18.33 & 11.55 & 4.54 & 25.34 & 51.76 & 5.96 \\
\hline LSD (\%5) & NS & 0.703 & 0.370 & 0.668 & 0.070 & 0.103 \\
\hline
\end{tabular}

*Same letters in a column are not significantly difference at 0.05 probability level

The obtained results indicate that the palmitic acid concentration of soybean varieties varied between 10.59 and $12.04 \%$ in the main cropping season and $10.76-12.23 \%$ in double cropping season (a two-year average). The differences between the varieties were statistically significant in both main and double cropped soybean (Table 1 and Table 2). The highest palmitic acid content was found in variety llksoy and lowest in Turksoy and Arısoy varieties during cropping system. Palmitic acid content was higher in double cropped soybean $(11.55 \%)$ than in main cropped soybean (11.29\%).

Based on the results, the average of two-year study reported that the content of stearic acid varied between 3.11-4.52 $\%$ in the main cropped and 3.94-4.87 was recorded in the double cropped growing season of soybean (Table 1 and 2). while stearic acid was $4.06 \%$ in main cropped growing season, it increased to
$4.54 \%$ at double cropped soybean. The profile of fatty acid in soybean oil vary depending on variability of environmental conditions and genetic factors (Bellaloui et al., 2015). Bellaloui et al. (2013) found that high temperature in growing season resulted in higher palmitic and stearic acid content in soybean oil.

Statistically significant differences were found among soybean varieties for oleic acid rate during both growing seasons. The average of two-year study reported that the oleic acid percentage ranged from $27.02-34.09 \%$ in the main cropped soybean and $22.69-29.51 \%$ in doubled cropped soybean (Table 1, Table 2 and Fig. 1). The highest oleic acid content was found in Ilksoy (34.09\%) and Turksoy (29.51\%) varieties, while lowest in Cinsoy variety (27.02 and $22.69 \%$ ) in main and double cropped soybean, respectively. The average oleic acid content of soybean varieties was $30.06 \%$ during main croppping system and $25.34 \%$ 


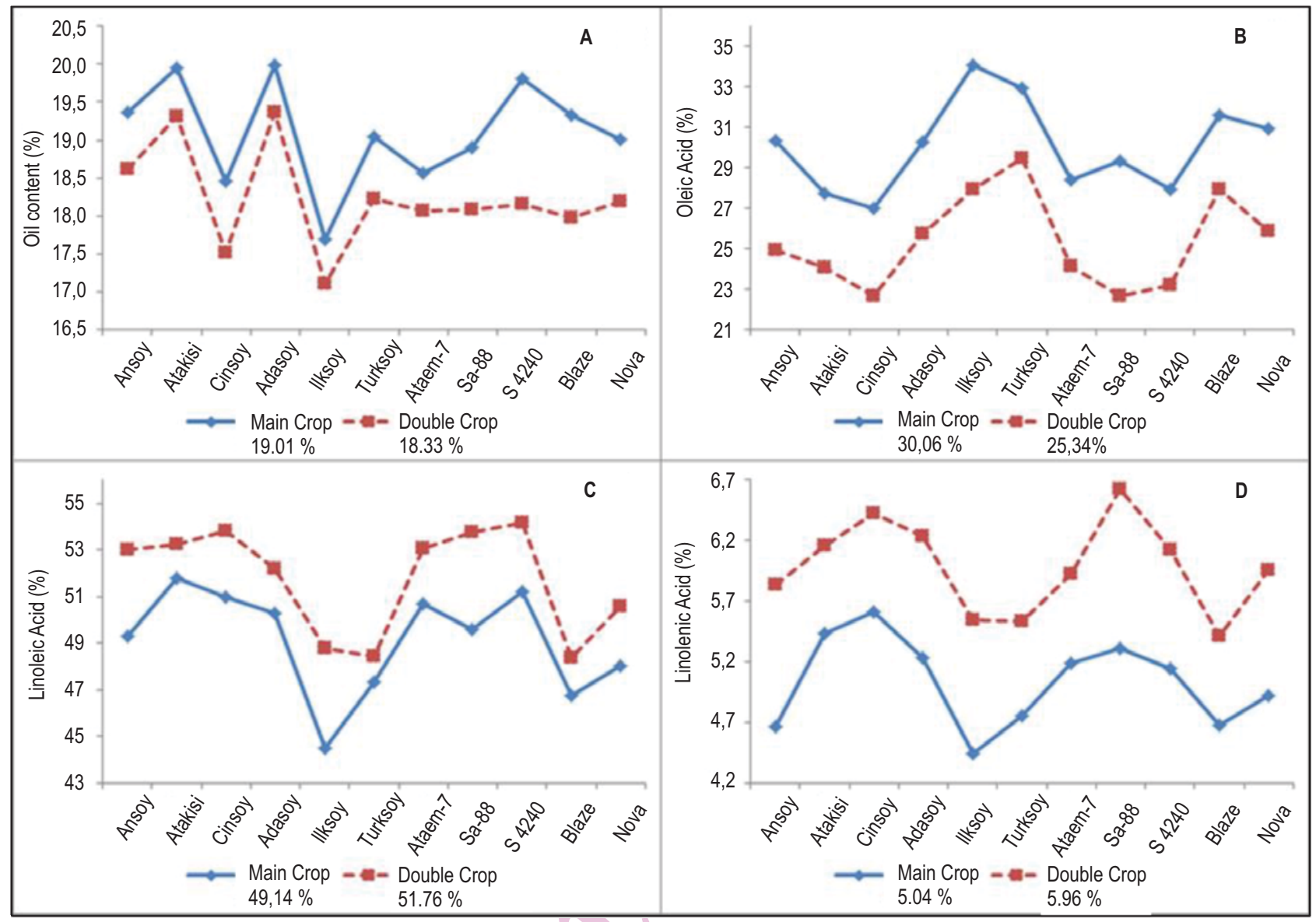

Fig. 1 : Oil content, oleic, linoleic and linolenic acid of some soybean varieties grown as main and double crop

during double cropped soybean. Oleic acid rate increased up to $18.6 \%$ more in the main cropped than double soybean. The oleic acid content of soybean varieties was affected by cropping system. Kane et al. (1997) reported that early planting increased oleic acid percentage, but delayed planting decreased oleic acid content. Similar results were reported by Jung et al. (2012); Bellaloui et al. (2013); Kurt et al .(2016) and Gulluoglu et al. (2016 and 2017).

The difference between the varieties were statistically significant for linoleic and linolenic acid content in both main and double cropping systems. The linoleic acid content of soybean varieties varied between 44.5 and $51.80 \%$ in main cropping growing season and between $48.40-54.14 \%$ in double cropping system. The highest linoleic acid content was found in Atakisi (51.80\%), S 4240 (51.24\%) and Cinsoy (50.98\%) in main cropping season and from S. 4240 (54.14\%) in doubled cropping soybean. The average linoleic acid content of soybean varieties was $49.14 \%$ in main cropped soybean and $51.76 \%$ in double cropped growing season (Table 1, Table 2 and Fig. 1). The linoleic acid percentage in double cropped growing season was higher as compared to main cropped soybean.
The linolenic acid content in soybean varieties ranged from 4.44 to $5.61 \%$ in main cropped and from 5.41 to $6.62 \%$ in double cropped soybean. The highest linolenic acid content was observed in Cinsoy (5.61\%) and Atakisi (5.44\%) during the main cropped growing season and from Sa.88 (6.62\%) in doubled cropped soybean. However, the average linolenic acid content was $5.04 \%$ in main cropped soybean, which increased to $5.96 \%$ in the double cropped soybean (Table 1, Table 2 and Fig. 1). The linolenic acid content among the varieties was higher in double cropped soybean (planting delayed to June) than the main cropped soybean (planting in May). The linoleic and linolenic acids content in soybean varieties were grown in different cropping system differed and were affected by temperature.

Generally, fatty acid composition of soybean oils is not constant. Kane et al. (1997) reported that the fatty acid content of soybean oils varied depending on several environmental and genetics factors. The environmental variability, particularly differences in temperature at the time of seed development cause major differences in linoleic and linolenic acid rates of seed oil in soybean. Bellaloui et al. (2011), Jung et al. (2012) and Bellaloui et 
al. (2015) reported that under irrigated condition, early planting decreased linoleic and linolenic acids content of soybean oil compared to late planting.

In this research, the air temperature was high in August than in September at the experimental area. Linolenic and linolenic acids content was reduced by high air temperature during seed filling period. For this reason, linoleic and linolenic acid percentage was higher in double than the main cropped growing season. Similar results were reported by other researchers (Kane et al., 1997; Bellaloui et al., 2011; Jung et al., 2012; Bellaloui et al., 2013; Bellaloui et al., 2015).

The stearic and palmitic acid, and linoleic and linolenic acid contents were higher in double cropped soybean than in main cropped soybean. On the other hand, the average of oil content, oleic acid rate was higher in main cropped soybean than in double cropped soybean. However, the results indicated that different growing seasons could be practiced as a substitute in determining the environmental stability of soybean genotypes.

\section{Acknowledgments}

This work was supported by the Atlas Seed Company, Adana-Turkey. We would like to express our sincere thanks and appreciation to Serdar Mart, General Director of Seed Company. Also, we would especially like to thank Dr. Mehmet Erdogmus for his technical assistance, The Black Sea Research Institute, Samsun-Turkey

\section{References}

AOCS (American Oil Chemists' Society): Official and recommended methods. American Oil Chemists' Society Press, Champaign, IL, USA (1989).

Arioglu, H.H.: The oil seed crops growing and breeding. The Publication of University of Cukurova, Faculty of Agriculture, No: A-70, Adana. Turkey, p. 204 (2014).

Bellaloui, N., K.N. Reddy, A.M. Gillen, D.K. Fisher and A. Mengistu : Influence of planting date on seed protein, oil, sugars, minerals, and nitrogen metabolism in soybean under irrigated and nonirrigated environments. American J. Plant Sci., 2, 702-705 (2011).
Bellaloui, N., A.M. Mengistu and A. Kassem : Effects of genetics and environment on fatty acid stability in soybean seed. Food Nutr. Sci., 4,165-175(2013).

Bellaloui, N., H.A. Bruns, H.K.Abbas, A. Mengistu, D.K. Fisher and K.N. Reddy: Agricultural practices altered soybean seed protein, oil, fatty acids, sugars and minerals in the mid-south USA. Front. Plant Sci., 6, 1-14 (2015).

Gulluoglu, L., H.Bakal, B.Onat, A. EL Sabagh and H. Arioglu : Characterızation of peanut (Arachis hypogaea L.) seed oll and fatty acids composition under different growing season under Mediterranean environment. J. Exp. Biol. Agr., 4, 564- 571 (2016).

Gulluoglu, L., H. Bakal, A. EL Sabagh and H. Arioglu: Soybean managing for maximize production : Plant population density effects on seed yield and some agronomical traits in main cropped soybean production. J. Exp. Biol. Agr., 5, 31-37 (2017).

Jung, G.H., J.E. Lee, D.W. Kim, T.Y. Hwang,K.S. Lee, B.M. Lee ,H.S. Kim ,Y.U. Kwon and S.L. Kim: Effect of planting date, temperature on plant growth, isoflavone content, and fatty acid composition of soybean. Korean J. Crop Sci., 57, 373-383(2012).

Kane, M.V., C.C. Steel, L.Grabau , C.T. Mac Kown and D.F. Hildebrand: Early-maturing soybean cropping system: III.protein and oil contents and oil composition. Agron. J., 89, 464-469(1997).

Kurt, C., H. Arioglu, T. Erdem, M.R.Akkaya, A. El Sabagh and M.S Islam: A comparative study of fatty acid extraction methods of sesame (Sesamum indicum L.) varieties grown under Mediterranean environment. J. Exp. Biol. Agricul. Sci., 4, 589-593(2016).

Neff, W.E. and G.R. List: Oxidative stability of natural and randomized high-palmitic and high-stearic-acid oils from genetically modified soybean varieties, JAOCS, 76, 825-831 (1999).

Sarnaik, S.S., P.P. Kanekar, V.M. Raut, S. P.Taware, K. S. Chavan and B.J. Bhadbhade: Effect of application of different pesticides to soybean on the soil microflora. J. Environ. Biol., 27, 423-426 (2006).

Schnebly, S.R. and W.R.Fehr: Effect of years and planting dates on fatty acid composition of soybean genotypes.Crop Sci. America, 33, 716-719 (1992).

Sultan, S.M., N. Dikshit and U.J. Vaidya: Oil content and fatty acid composition of soybean (glycine max I.) genotypes evaluated under rainfed conditions of kashmir himalayas in India. J. Appl. Nat. Sci., 7, 910-915.(2015).

Wilson,R.F.: Seed composition. In : Soybean : Improvement, production, and uses (Eds. : H.R. Boerma and J.E. Specht). Agron. Monogr. No. 16. ASA-CSSA-SSSA, Madison, WI, pp.621-677 (2004). 